\title{
Density-dependence in a population of Fucus distichus
}

\author{
P. O. Ang, Jr* , R. E. De Wreede \\ Department of Botany, University of British Columbia, Vancouver, British Columbia, Canada V6T 1 Z4
}

\begin{abstract}
Regulation of a Fucus distichus L. emend. Powell population is probably mediated through a density-dependent mortality of the recruits. Blocks seeded with different densities of germlings of $F$. distichus and cleared plots with naturally occurring recruits of different densities and with artificially thinned densities were used to monitor the effect of density on mortality and growth among recruits in a population of F. distichus in False Creek, Vancouver, British Columbia, Canada. In the first 2 mo of development, germlings on the high density blocks experienced a lower mortality than those on the low density blocks. At later stages $(>2 \mathrm{~mol}$, the effect of density on mortality was reversed. Plants recruited into the cleared plots were $>1 \mathrm{~mm}$ in length and they also experienced a positive effect of density on mortality. In both the density blocks and cleared plots, plant mortality eventually became independent of plant density. Plant growth rate was generally not related to density but was related to plant size (length). There was a large variation in the sizes of the plants. All 3 measures of size inequality: zero-centered skewness, coefficient of variation, and Gini coefficient are significantly correlated. Plants in both the density blocks and cleared plots showed a slight tendency towards a more normal or positively skewed size distribution from fall 1986 to spring 1987, probably due to an increased mortality of the smaller plants during this time. The mechanism of dominance-suppression and difference in the intrinsic growth rate or timing of settlement probably all contributed to the inequality in size distribution.
\end{abstract}

\section{INTRODUCTION}

The effect of density on mortality and growth has been assessed in a number of studies on algal populations. Mortality is generally found to be positively correlated with density (Black 1974, Chapman \& Goudey 1983, Chapman 1984, Schiel 1985, Dean et al. 1989, Reed 1990). Both positive (Schiel \& Choat 1980, Schiel 1985) and negative relationships (Dean et al. 1989, Reed 1990) with growth have been reported. Fewer studies have looked at the effect of density on reproduction and the results are not consistent (e.g. compare Schiel 1985 with Reed 1990). Most of these studies, however, involved plant recruits which were visible to the unaided eye. Density effect at the micro-

\footnotetext{
- Present address: Fisheries Research Laboratory, Fisheries and Oceans Canada, PO Box 550, Halifax, Nova Scotia, Canada B3J 2 S7
}

scopic stage is little known. Reed et al. (1991) pointed out the importance of detailed information on densitydependent processes. Only with an understanding of the response of different algal developmental stages to density can their responses to other environmental factors be better evaluated.

In this paper, we report on an experiment in which settling blocks were seeded with different known densities of germlings of Fucus distichus L. emend. Powell, and on clearings with naturally occurring recruits of different densities. We address questions on the effect of density on plant mortality and growth, both at the microscopic and macroscopic stages. None of the experimental plants became reproductive during this part of the study. However, given that reproduction was significantly correlated with plant size (see Ang 1991a, 1992), an indirect evaluation of density. dependent regulation of reproduction is assessed through the effect of density on plant size (length) that is mediated through its effect on plant growth. 


\section{MATERIALS AND METHODS}

The study area. is located along the southern seawall of False Creek, Vancouver, British Columbia, Canada $\left(49^{\circ} 17^{\prime} \mathrm{N}, 123^{\circ} 7^{\prime} \mathrm{W}\right)$. The wall supports an almost pure stand of Fucus distichus which forms a distinct zone (hereafter referred to as the Fucus zone) 1.5 to $2 \mathrm{~m}$ in width along the seawall $2.5 \mathrm{~m}$ above the Lowest Normal Tides (LNT).

Seeded density blocks. Settling blocks of $5 \times 5 \times 1 \mathrm{~cm}$ were made out of chips of granite collected from the seawall around the study area. These chips were cemented together with Poly Cement (Le Page's Limited, Bramalea, Ontario, Canada) and washed in seawater and freshwater as described in Ang (1991a). Receptacles from plants haphazardly collected in the field in July, November 1986, and May 1987 were cut and placed in a mesh bag suspended above the settling biorks in the aquaria with filtered seawater and kept in the growth chamber at $16 \mathrm{~h}$ light: $8 \mathrm{~h}$ dark, at $15^{\circ} \mathrm{C}$, under low light $\left(40 \mu \mathrm{E} \mathrm{m}^{-2} \mathrm{~s}^{-1}\right)$. To achieve different settling densities of the germlings on the blocks, the number of receptacles placed in the mesh bags was varied. The actual number of receptacles placed in any mesh bag, however, was not counted. The water was aerated to create some water motion within the aquaria.

Germlings were discharged from the receptacles within 2 to $3 \mathrm{~d}$. Each block was examined under the stereo-microscope for density of settled germlings. As expected, distribution of germlings on the blocks was uneven. Different numbers of germlings settled on different blocks. As much as possible, the number of all germlings on each block was counted with a grid divided into 25 squares of $1 \mathrm{~cm}^{2}$. However, blocks with a very high density of germlings were subsampled: only 2 to 3 randomly chosen squares were counted. The mean from these subsamples was taken as representing the density in the block. Based on the range of settling densities, 21 blocks were selected and grouped into 3 groups with 7 replicates each to represent low $\left[5.75 \pm 1.64\right.$ germlings $\mathrm{cm}^{-2}$ (mean $\left.\left.\pm \mathrm{SE}\right)\right]$, mid $(165.43$ \pm 31.26 germlings $\left.\mathrm{cm}^{-2}\right)$ and high (2555.29 \pm 512.99 germlings $\mathrm{cm}^{-2}$ ) settling densities. Initial size (length in $\mu \mathrm{m}$ ) of 3 to 20 germlings in each block was measured under the stereo-microscope.

These density blocks were then outplanted to the Fucus bed and placed in cement holding molds in 7 sets. Each set had 4 blocks: high, mid, low density blocks plus a control, unseeded block. The control blocks served as a measure of natural recruitment. Each of the 7 sets of blocks was randomly located within a $100 \times 1 \mathrm{~m}$ strip of the Fucus bed. No 2 sets of blocks were close enough $(<1 \mathrm{~m})$ to each other to suspect any physical interference, such as shading, between them.
The first batch of 21 seeded density blocks was outplanted in July 1986 but none of the germlings survived the summer. The second batch was outplanted in November 1986, and many of the germlings survived through the subsequent winter, spring and summer 1987. A third batch was outplanted in May 1987, but only a few germlings survived through July, and none survived through September 1987. All the analyses reported here are therefore based on data from the second batch of density blocks.

Every 2 mo, from November 1986 to November 1987, the blocks were taken back to the laboratory to be examined for changes in the density and sizes of the germlings (plants). These blocks were removed from the site at low tide and were placed immediately in boxes. Extreme care was taken to ensure that these blocks remained in place inside the covered boxes during transport $(<1 \mathrm{~h})$. They were then placed in the aquarium upon arrival at the laboratory. After November 1987, sizes of the surviving plants were large enough so monitoring of these blocks was continued in situ. Monitoring was terminated in June 1989 after the last plant disappeared from the block.

Natural density squares. Fourteen $50 \times 50 \mathrm{~cm}$ permanent plots in the Fucus bed were cleared and burned using a propane torch in September 1985 to remove all plants and animals. Recruits $\geq 1 \mathrm{~mm}$ long started to appear in February 1986, but were not even in their distribution within the plot. The distribution of plants among different plots was also not the same. Some plots had more patches of recruits than the others. Each cleared plot was divided into 25 squares of $10 \times 10 \mathrm{~cm}$. Only the inner 9 squares were used to minimize 'edge' effects. By April 1986, many squares among the 14 plots were still completely devoid of visible recruits and were therefore dropped from further examination. Only 31 remaining squares with visible recruits were further monitored for the change in plant density and size.

The number of plants in most squares increased from April to July 1986. Based on July density, the squares were grouped arbitrarily into 2 categories, 23 of them as high density ( $>0.25$ plant $\mathrm{cm}^{-2}$ ) and 8 as low density $\left(\leq 0.25\right.$ plant $\left.\mathrm{cm}^{-2}\right)$ squares. It was not possible to have an even distribution of number of high and low density squares within each plot. Since patches of recruits were likely to have settled randomly into each plot and the size of each patch was defined by the $10 \times 10 \mathrm{~cm}$ square, each square was treated as an independent sample.

To test the response of plants to thinning, the density of recruits in 9 high density squares was artificially thinned in July to 0.25 plant $\mathrm{cm}^{-2}$ (or 1 plant per $2 \times$ $2 \mathrm{~cm}$ ). This was achieved by further dividing the squares in to 25 subplots of $2 \times 2 \mathrm{~cm}$ and then scraping off all except 1 plant in each subplot. 
As much as possible, sizes of all plants in each square were measured. In many cases however, this was not practical, e.g. density was too high. For these cases, at least 20 plants from each square were randomly selected and measured. All density squares were monitored every 2 to 3 mo from April 1986 to November 1987

Statistical analyses. Mortality is expressed as a percentage difference in the density of germlings (plants) between 2 consecutive times in each density block or square. Growth is expressed as the difference in the mean length of germlings (plants) between 2 times. Because the time intervals between sampling were not always equal, both mortality and growth data were standardized to a time interval of 2 mo.

All data were tested for normality (Lilliefor's test) and equality of variances (Bartlett's test). If necessary, data were transformed to meet the assumptions of the parametric statistics. Two-level nested analysis of variance (ANOVA) was used to test the difference in the mean size of plants among density blocks or squares. Linear regression lines were fitted to describe the relationship between mortality, length, growth and density. In most cases, density data were log-transformed to improve the linear fit of the regression curve.

The pattern of change in plant length over time for plants in different initial densities was compared based on the test for the homogeneity of slopes of the regression lines using the following model of analysis of variance (ANOVA) (Kleinbaum \& Kupper 1978, Wilkinson 1988):

$$
Y=\text { constant }+ \text { Treatment }+X+\text { Treatment } \times X
$$

where $Y$ is the dependent variable, i.e. plant length; Treatment is the initial density; and $X$ is the independent variable (or covariate), i.e. plant density. The effect of plant density on plant growth rate over time was also compared using a similar model with $Y$ = plant growth rate, Treatment $=$ time period, and $X=$ plant density. Growth rates were based on difference in the mean length of plants between 2 consecutive times, and plant lengths were based, in most cases, on random individuals within each block or square. Hence, although measurements were made on the same blocks or squares repeatedly over time, these measurements can be treated as independent samples (Underwood 1981). Pooling of data is justified if the interaction between the treatment and the covariate is not significant ( $\mathrm{p}_{\text {Treatment } x} x>0.05$ ). Changes in the size distribution (size inequality) among plants in the density blocks and squares were assessed by zero centered skewness $\left(g_{1}\right)$ (Ford 1975, Schiel 1985), coefficient of variation (CV) (Edmeades \& Daynard 1979) and Gini coefficient $(G)$ (Weiner \& Solbrig 1984).

All statistical analyses, except the Gini coefficient, were performed using SYSTAT (Wilkinson 1988). The Gini coefficient was calculated with a program written in the spreadsheet Lotus 123.

\section{RESULTS}

\section{Seeded density blocks}

The Fucus population from False Creek experienced a high recruitment rate in November 1986 (see Ang 1991a, Fig. 11). When the seeded blocks were outplanted during that time, they were also settled by new recruits from the field. This was confirmed by the presence of recruits on the control blocks. Although the locations of the original germlings on the density blocks were initially mapped, the presence of new recruits occasionally presented some problems in the identification of the original germlings. However, the older germlings were generally larger than the new recruits on the control blocks. None of the latter was $>320 \mu \mathrm{m}$ in length. When there was doubt in determining whether a germling was an old one or a new recruit, the size of $320 \mu \mathrm{m}$ was used as a cut off. All plants considered to be new recruits were not counted and were subsequently physically removed from the block. Doing this may have also excluded some of the older but smaller germlings and would result in overestimation of mortality. On the other hand, the condition in the density (experimental) blocks may be more benign than that in the control blocks such that new recruits in the density blocks may be growing faster than those in the control blocks. Some new recruits could therefore be larger than the cut off size of $320 \mu \mathrm{m}$ at the time of sampling and thus could be counted as old germlings. This would result in the underestimation of mortality. These problems were probably not critical as a decision to distinguish new from old germlings needed to be made only $<25 \%$ of the time. These were potential problems only from November 1986 to March 1987. After March, the original germlings on the density blocks had grown enough to be easily distinguished from any new recruits. These potential problems were also more likely to be encountered in the mid and low density blocks. In high density blocks, because the germlings were so crowded, there was probably no room for new recruits to settle, and none was assumed to have done so.

Plant density declined gradually over time (Fig. 1). From September 1987 on, the density among blocks was no longer significantly different (Kruskal-Wallis 1way ANOVA, $d f=2, p=0.356$ ). At the initial phase of development, i.e. from November 1986 to January 1987, mortality rate of the germlings was significantly negatively related with density (Fig. $2 \mathrm{~A}$ ). This relation- 


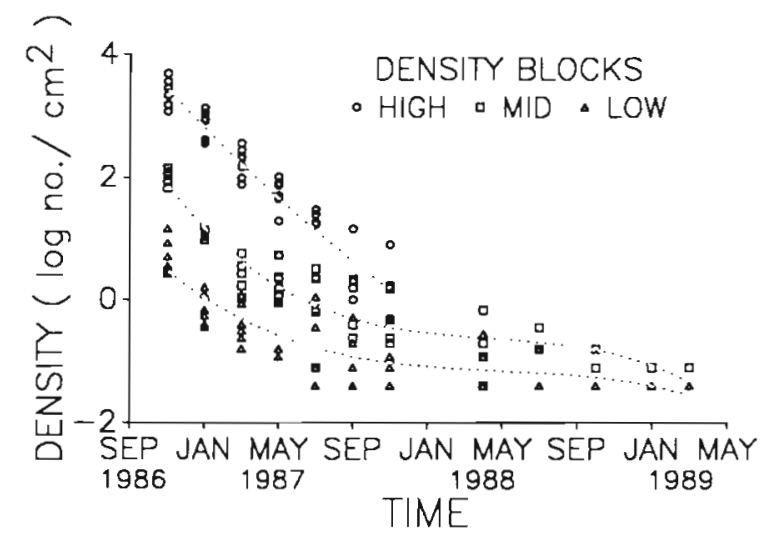

Fig. 1. Fucus distichus. Density of plants in each density block over time. Dotted lines are curves fitted by second order polynomial for high density blocks and third order polynomial for mid and low density blocks to indicate the general pattern of decline in density among the 3 groups of density blocks

ship was reversed after January. From January to November 1987, germlings (plants) in low density blocks suffered lower mortality than those in high density blocks. However, a positive relationship between mortality and density was significant only from January to March 1987 (Fig. 2B). Plants from mid density blocks suffered intermediate rates of mortality throughout the experimental period. The regression lines describing the significant mortality and density relationship accounted only for $<35 \%$ of the variation within the data. Polynomial regression did not significantly improve the fit of the curve. Hence, although mortality was significantly related to density, the effect of density on mortality was not strong. Mean mortality rates among plants in the 3 density blocks were not significantly different most of the times, except from November 1986 to March 1987 (ANOVA, $p<0.05$ )

There was no significant relationship between plant length and plant density at each bimonthly sampling time from November 1986 to November 1987 (linear regression, p >0.05) except for September 1987, where the positive relationship was marginally significant (linear regression: $\log$ length $=0.978+0.243 \log$ den sity, $n=10, r^{2}=0.412, p=0.045$ ). When first seeded in November 1986, the initial lengths of the plants (germlings) in all density blocks were not significantly different (Table 1A). However, variation in mean plant size increased over time and sizes of the plants among density blocks became significantly different in January 1987, just 2 mo after seeding (Table 1B). This difference was mainly due to

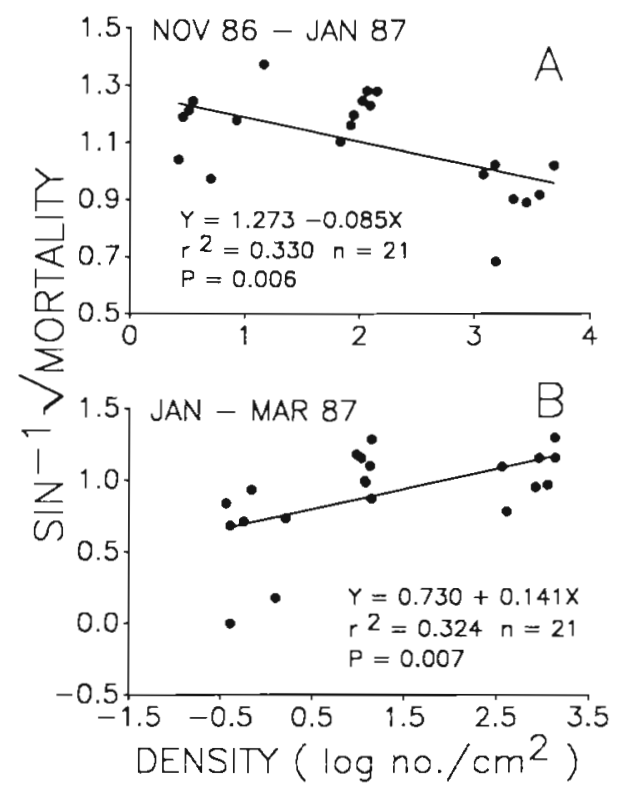

Fig. 2. Fucus distichus. Linear regression of plant mortality vs plant density in the density blocks at different time periods. (A) November 1986 to January 1987, (B) January 1987 to March 1987

increased size variation among plants in the high density blocks. At this time, sizes of the plants among the high density blocks were significantly different (ANOVA, $F_{5,66}=9.793, \mathrm{p}<0.001$ ), whereas sizes of the plants among either the mid or low density blocks were not (ANOVA, $F_{6.63}=0.87, \mathrm{p}=0.522$ for mid density blocks: $F_{2.10}=0.534, p=0.597$ for low density blocks). Sizes of the plants among the mid density

Table 1. Fucus distichus. Results of 2-level nested ANOVA on the difference in the mean length of plants among blocks seeded in November 1986 with different initial densities of germlings. Sampling periods included in each analysis are indicated. Sources of variation are among blocks with different initial seeding densities (among densities) and among plants within blocks with similar initial density (among blocks). Length data were log-transformed

\begin{tabular}{|lrrrr|}
\hline Source of variation & df & MS & $F$ & $p$ \\
\hline A. November 1986 & & & & \\
Among densities & 2 & 0.006 & 0.617 & 0.541 \\
Among blocks & 18 & 0.009 & 0.935 & 0.531 \\
Error & 189 & 0.010 & & \\
B. January 1987 & & & & \\
Among densities & 2 & 0.345 & 20.969 & $<0.001$ \\
Among blocks & 13 & 0.049 & 2.811 & 0.001 \\
Error & 139 & 0.016 & & \\
C. November 1987 & & & & \\
Among densities & 2 & 0.457 & 3.234 & 0.042 \\
Among blocks & 8 & 0.383 & 2.706 & 0.009 \\
Error & 136 & 0.141 & & \\
& & & & \\
\hline
\end{tabular}




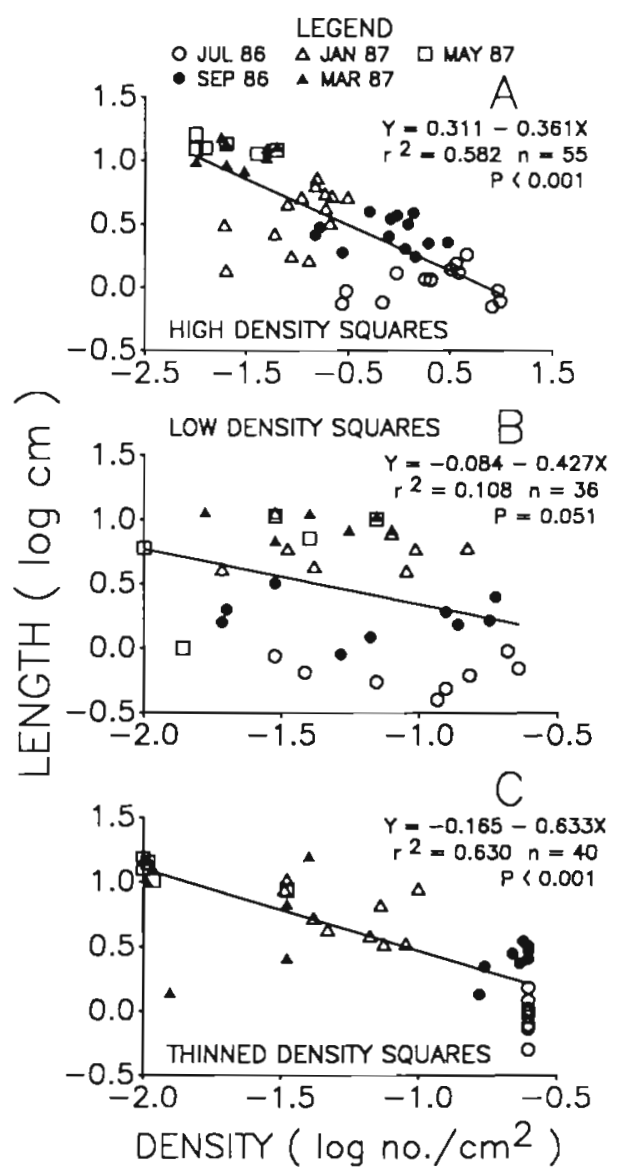

Fig. 3. Fucus distichus. Pattern of change in plant length with the decline in plant density in each group of density blocks over time

blocks became significantly different 2 mo later in March 1987 (ANOVA, $F_{6,133}=4.918, p<0.001$ ), and those among low density blocks another 4 mo later in

Table 2. Fucus distichus. Correlation matrices showing Pearson correlation coefficient $(r)$ among the 3 measures of size inequality, Skewness $\left(g_{1}\right)$, Coefficient of variation (CV), and (iini coefficient $(G)$, for plants in the density blocks. All correlation coefficients are highly significant $(p<0.001)$

\begin{tabular}{|lcc|}
\hline Measures & CV & $G$ \\
\hline High density blocks $(\mathrm{n}=39)$ & & \\
$g_{1}$ & 0.534 & 0.510 \\
$\mathrm{CV}$ & & 0.986 \\
Mid density blocks $(\mathrm{n}=43)$ & & \\
$\quad g_{1}$ & 0.687 & 0.578 \\
$\mathrm{CV}$ & & 0.974 \\
Low density blocks $(\mathrm{n}=35)$ & & \\
$g_{1}$ & 0.544 & 0.570 \\
$\mathrm{CV}$ & & 0.914 \\
All data $(\mathrm{n}=117)$ & & \\
$g_{1}$ & 0.578 & 0.554 \\
$\mathrm{CV}$ & & 0.956 \\
\hline
\end{tabular}

July 1987 (ANOVA, $F_{5,58}=2.541, \mathrm{p}=0.038$ ). Plants from different density blocks remained significantly different in sizes until November 1987 (Table 1C). There was no consistent pattern that plants in high density blocks were larger than those in the mid or low density blocks (Fig. 3). By April 1988, only one high density block remained so no comparison can be made between the sizes of the plants in high versus those in mid and low density blocks. Mean sizes of the remaining plants in mid (57.8 $\pm 13.5 \mathrm{~mm}$, mean $\pm \mathrm{SE})$ and low $(78.1 \pm 25.9 \mathrm{~mm})$ density blocks did not differ significantly (2-level nested ANOVA, between densities, $F_{1,36}=1.938, \mathrm{p}=0.172$ ).

The pattern of change in plant length for plants in all 3 density blocks followed a negative slope as plant density declined over time (Fig. 3). The differences among these slopes, which are measures of rates of change, are only marginally significant (ANOVA, Initial Density $\times$ Density, $F_{2,110}=3.177, \mathrm{p}=0.046$ ). The difference occurred mainly between plants in the high and low density blocks (ANOVA, Initial Density $x$ Density, $F_{0,69}=6.001, \mathrm{p}=0.017$ ).

All 3 measures of size inequality (sensu Bendel et al. 1989), $g_{1}, C V$, and $G$, were significantly correlated (Table 2). Oniy the results of the shape of size distribution (Skewness) are presented here. Skewness, ranging from negative to positive, gives more information on whether the inequality in the size distribution is due to the presence of more large plants and fewer small plants (negative skewness) or more small plants and fewer large plants (positive skewness). The distribution of plant length among and within each set of density blocks was highly variable (Fig. 4), ranging from being negative to positively skewed at the early germling stage in November 1986 to generally more normal to positively skewed towards spring (March to May 1987). The distribution became more variable again towards summer and fall of 1987

Mean growth rate of plants from different initial densities increased from November 1986 to February 1988, and then showed some decline after June 1988 (Fig. 5). The effect of density on growth rates was not significantly different among times from November 1986 to July 1987 (ANOVA, Time $\times$ Density, $F_{3,62}=$ $0.339, p=0.797$ ), but was significantly different among times if a longer sampling period from November 1986 to November 1987 was considered (ANOVA, Time $x$ Density, $\left.F_{5.77}=7.898, \mathrm{p}<0.001\right)$. This suggests that the difference was mainly due to increased variation in the growth rate at later times. However, multiple regression analysis indicated that plant growth rate was not significantly related to plant density, but was significantly related to plant length (Table 3). The effect of density alone accounted for only $5 \%$ of the variation, whereas plant length alone accounted for about $19 \%$ 

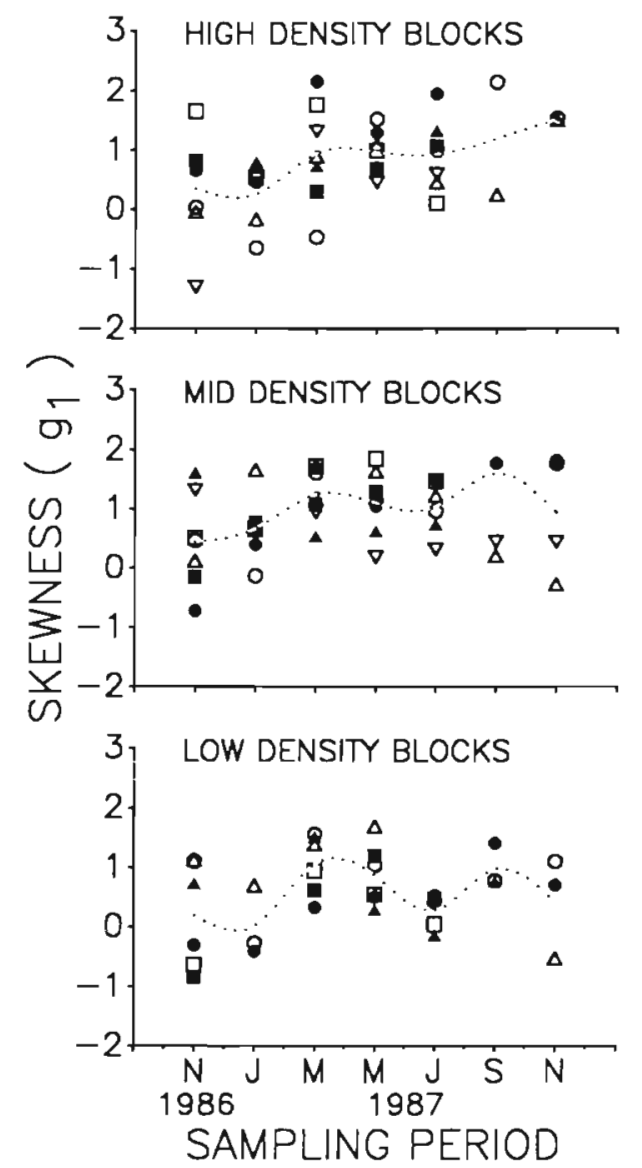

Fig. 4. Fucus distichus. Changes in the size distribution of the plants among the density blocks measured as zero-centered skewness. Each symbol represents the same block over different times. Dotted line connects the mean values for each sampling period

of the variation in plant growth. Similar results were obtained with growth rate expressed as a relative proportion of increase in plant size.

\section{Natural density squares}

The effect of density on mortality in plants in the cleared plots (density squares) was not significantly

Table 3. Fucus distıchus. Results of multiple regression on the effect of mean density and mean length on mean absolute growth over time among plants on the settling blocks

\begin{tabular}{|lrrrr|}
\hline Variables & df & $b$ & $r^{2}$ & \multicolumn{1}{c|}{$p$} \\
\hline Density + Length & 2,67 & & 0.193 & 0.001 \\
Density & 1,68 & -0.173 & 0.052 & 0.057 \\
Length & 1,68 & 0.919 & 0.192 & $<0.001$ \\
\hline
\end{tabular}

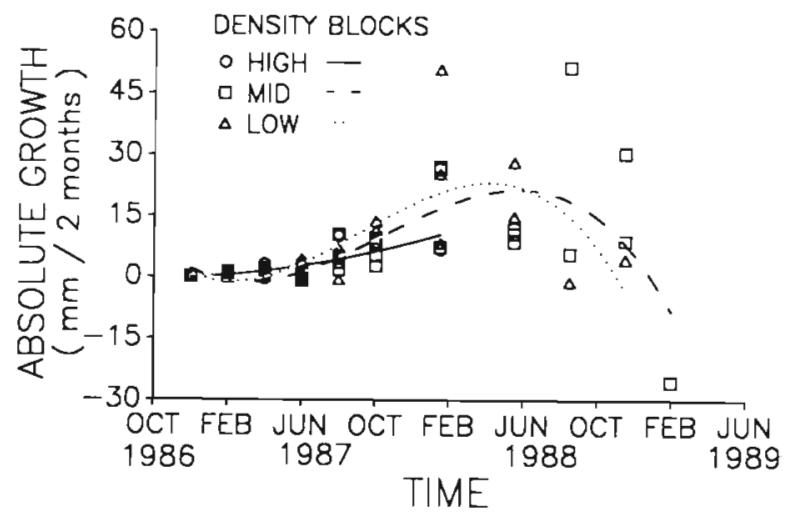

Fig. 5. Fucus distichus. Changes in the absolute growth rate of the plants in each density block over time. Curve lines are fitted by second order polynomial for high density blocks and third order polynomial for mid and low density blocks to indicate the general pattern of change in mean growth rates among respective density blocks

different among the 3 sets of squares with different initial densities (ANOVA, Initial Density $\times$ Density, $F_{2,106}$ $=0.964, p=0.385)$. The relation between plant density and mortality was significantly positive only for the data from July 1986 to January 1987 (Fig. 6). The effect of density on mortality was only marginally significant in July to September 1986 with only < $15 \%$ of the variation in mortality accounted for by density. The effect was stronger from September 1986 to January 1987 with increased percentage of variation ( $43 \%$ ) in mortality accounted for by density. Polynomial regression

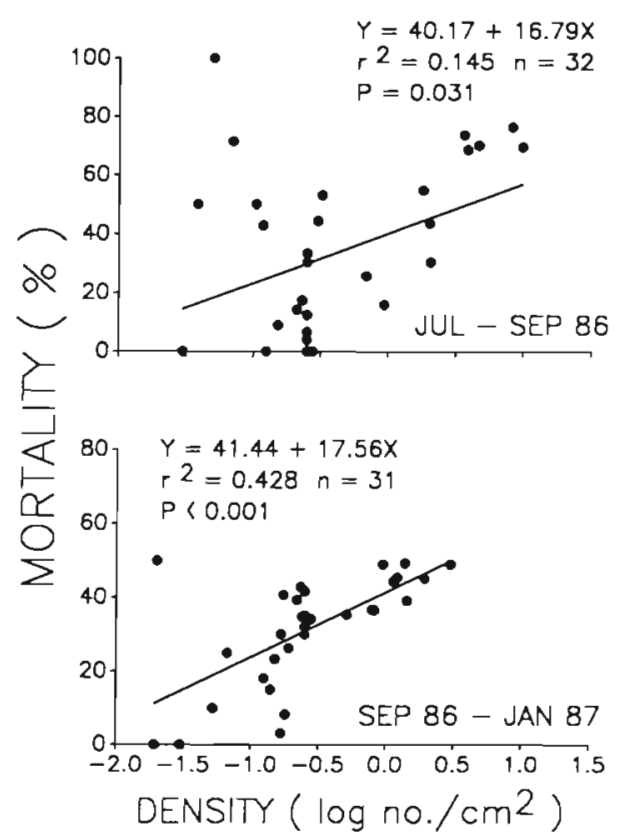

Fig. 6. Fucus distichus. Linear regression of plant mortality vs plant density in the density squares from July to September 1986 and from September 1986 to January 1987 
Table 4. Fucus distichus. Mean length $(\mathrm{cm} \pm \mathrm{SE}$ ) of plants among the density squares at different times. Number of squares ( $n$ ) for each density is given in parentheses

\begin{tabular}{|c|c|c|c|c|c|c|}
\hline \multirow[t]{2}{*}{ Date } & \multicolumn{6}{|c|}{ Density squares } \\
\hline & High & & Low & & Thinned & \\
\hline Jul 1986 & $1.12 \pm 0.09$ & (14) & $0.65 \pm 0.07$ & (8) & $0.96 \pm 0.10$ & (9) \\
\hline Sep 1986 & $2.87 \pm 0.21$ & (14) & $1.87 \pm 0.26$ & (8) & $2.67 \pm 0.21$ & (9) \\
\hline Jan 1987 & $4.07+0.49$ & (14) & $6.16 \pm 0.86$ & (8) & $6.08 \pm 0.91$ & (9) \\
\hline Mar 1987 & $11.50 \pm 0.85$ & (8) & $9.52 \pm 0.76$ & $(6)$ & $8.93 \pm 2.04$ & (9) \\
\hline May 1987 & $12.93 \pm 0.58$ & (7) & $6.98 \pm 1.73$ & (5) & $12.20 \pm 1.21$ & (5) \\
\hline
\end{tabular}

did not improve the fit of the curve. There was no significant relationship between plant density and mortality for the data from January to May 1987

Plants in all 3 density squares exhibited a wide range of sizes (Table 4). In July 1986. mean lengths of plants in density squares with similar initial density (i.e. among squares), as well as among squares with different initial densities (i.e. among densities) were significantly different (Table 5A). However, by March 1987, these differences were no longer significant (Table 5B).

Table 5. Fucus distichus. Results of 2-level nested ANOVA on the difference in the mean length of plants among density squares with different initial densities of recruits sampled in (A) July 1986 and (B) March 1987 Sources of variation are among squares with different initial densities of recruits (among densities) and among plants within squares with similar initial density (among squares). Length data were logtransformed

\begin{tabular}{|lrrrc|}
\hline Source of variation & df & MS & $F$ & $\mathrm{p}$ \\
\hline A. July 1986 & & & & \\
Among densities & 2 & 0.940 & 12.719 & $<0.001$ \\
Among squares & 28 & 0.381 & 5.151 & $<0.001$ \\
Error & 605 & 0.074 & & \\
B. March 1987 & & & & \\
Among densities & 2 & 0.165 & 1.211 & 0.308 \\
Among squares & 12 & 0.127 & 0.934 & 0.523 \\
Error & 42 & 0.137 & & \\
\hline
\end{tabular}

Table 6. Fucus distichus. Correlation matrices showing Pearson correlation coefficient $(r)$ among the 3 measures of size inequality, Skewness $\left(g_{1}\right)$, Coefficient of variation (CV), and Gini coefficient $(G)$, for plants in the density squares

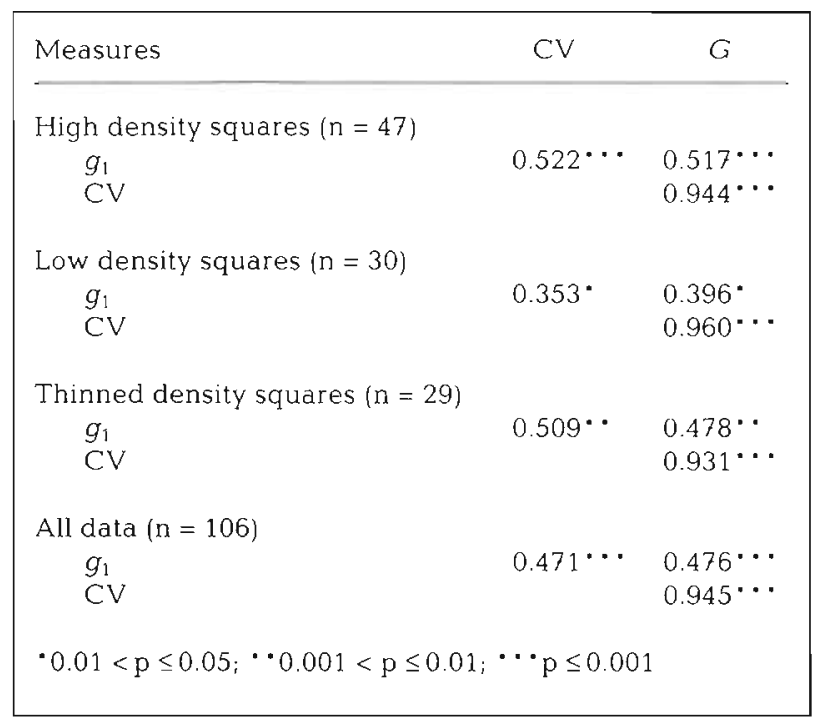

All 3 measures of size inequality were significantly correlated (Table 6). Again, only the results of the shape of distribution (skewness) are presented here. Size distribution among plants in all 3 density squares was highly variable, ranging from normal to positively skewed in summer (July 1986) to becoming negative to positively skewed in fall to winter (Fig. 7).
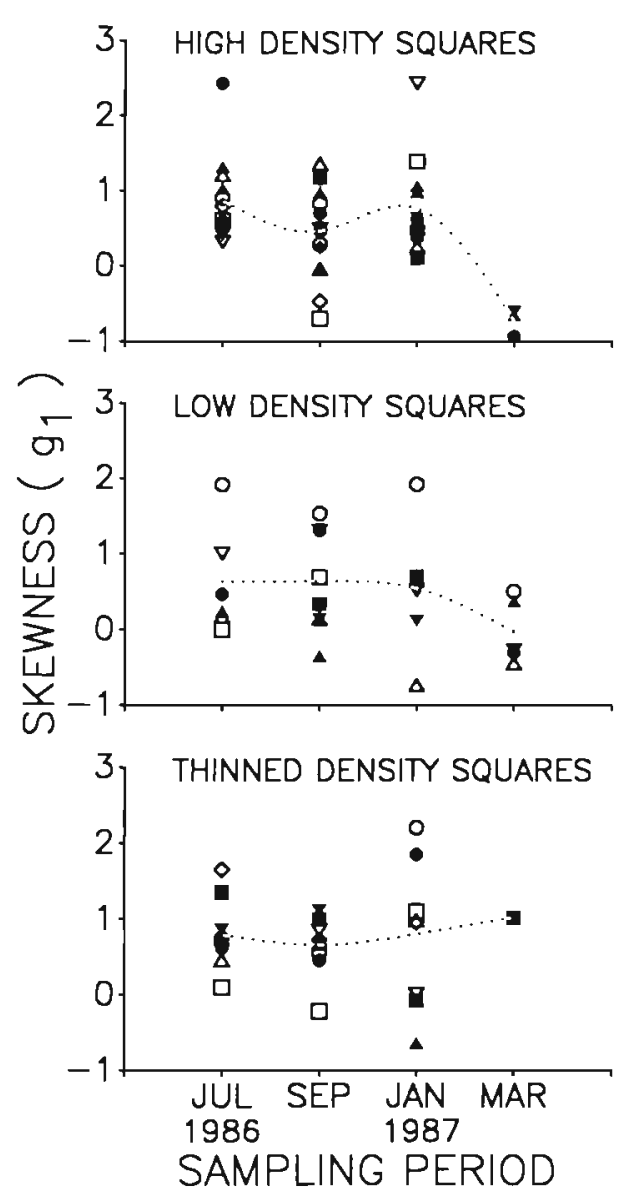

Fig. 7. Fucus distichus. Changes in the size distribution of plants in the density squares over time measured as zero centered skewness. Each symbol represents the same square over different times. Dotted line connects the mean values for each sampling period 


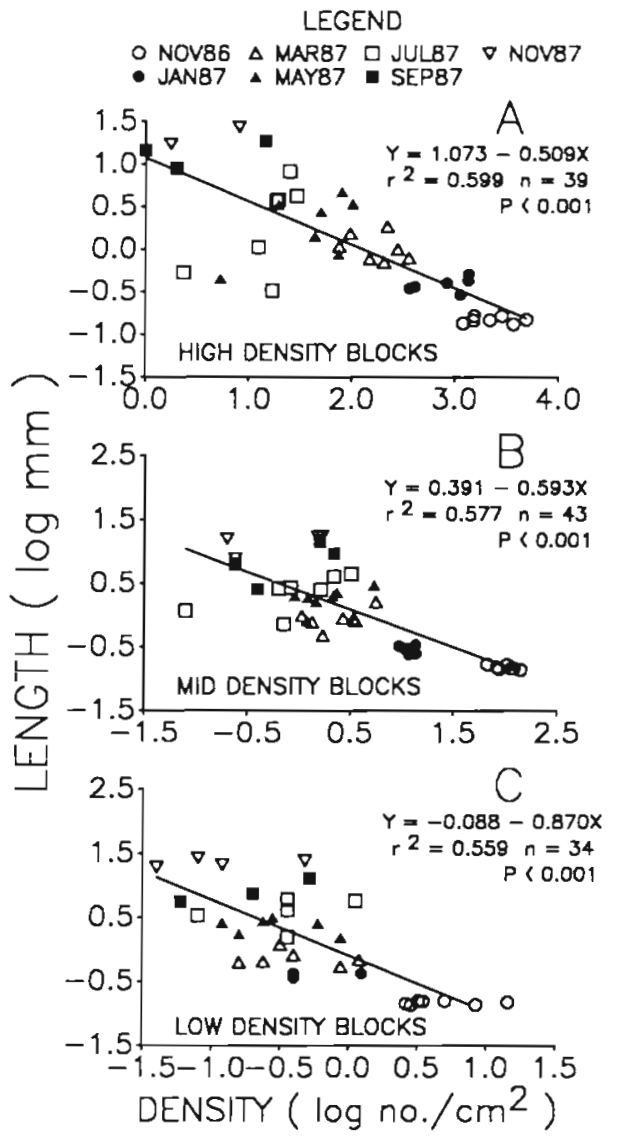

Fig. 8. Fucus distichus. Changes in plant length with the decline in plant density over time in each group of density squares

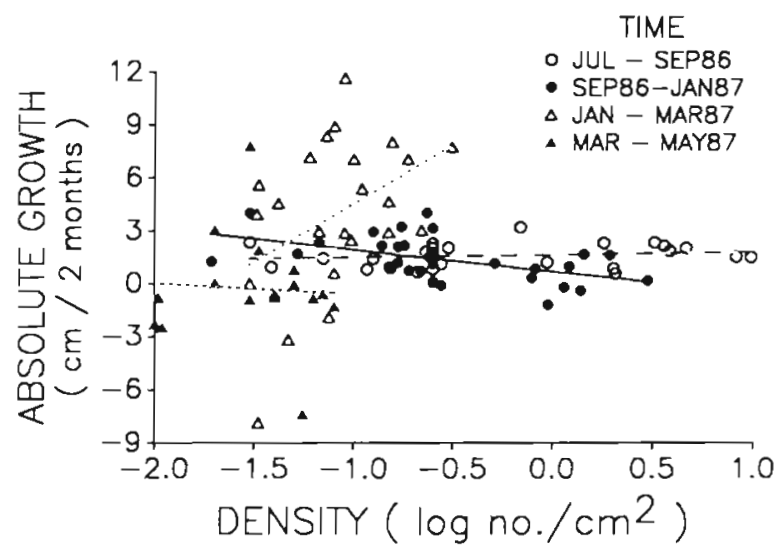

Fig. 9. Fucus distuchus. Changes in mean absolute growth rate of plants in each densily square over time. Regression lines relating the mean growth rate to density for each period are indicated. Regressions for July to September 1986 (- - ) and March to May $1987(\cdots \cdot)$ are non-sirgnificant $(p>0.05)$. Regression for September 1986 to January 1987 (-) : growth $=0.694-1.236 \log$ density, $n=30, r^{2}=0.257, p=0.004$ Regression for January to March $198 \vec{f}[\cdots \cdot)$ : growth $=$ $11.213+6647 \log$ density, $n=23, r^{2}=0.179, p=0.044$
There was no significant difference in the effect of plant density on plant length over time (ANOVA, Time $\times$ Density, $F_{4,121}=0.304, \mathrm{p}=0.875$ ). Similar to that observed in density blocks, plants increased in length as plant density declined (Fig. 8). However, the difference in the slopes relating plant length with plant density was marginally significant among the 3 density squares (ANOVA, Initial Density $\times$ Density, $F_{2,125}=$ $3.128, p=0.047$ ). Only in the high and the thinned density squares was the negative slope significantly different from 0 (Fig. 8).

The effect of plant density on mean plant grow th rate was significantly different over time (ANOVA, Time $x$ Density, $F_{3,91}=5.007, p=0.003$ ) so the data cannot be pooled. This relationship was negatively significant from September 1986 to January 1987, and positively significant from January to March 1987 (Fig. 9). However, only $<26 \%$ of the variation in growth rate was accounted for by density.

\section{DISCUSSION}

The range of densities of germlings seeded in the mid and low density blocks is within that observed in natural settling experiments. However, the range of density initially seeded in the high density blocks has not been observed in the field. Nevertheless the range of density in the high density blocks a few months after germlings were seeded is similar to ranges of density of small plants observed in the cleared plots, as well as in the permanent quadrats (see Ang 1991a). This suggests that the density range of germlings initially seeded in the high density blocks is probably realistic. It is conceivable that a high density of eggs could be discharged in clusters especially during re-submergence of fertile plants by the incoming tide.

Newly seeded germlings on the density blocks were microscopic. They became visible 4 mo later in March 1987 when they had grown to be $\geq 1 \mathrm{~mm}$ in length. Based on this information, macrorecruits that started to appear in February 1986 in the plots cleared in September 1985 were likely to have been recruited into the population at least 4 mo earlier in November 1985. The timing of recruitment would have coincided with the peak period of fertility of the population (Fig 5 of Ang 1991a). Subsequent appearances of new plants from April to July 1986 may have resulted from continuous recruitments or from the growth of germlings from the 'germling bank' (Ang 1991a).

Recruitment is believed to be one of the processes that regulate population structure (Roughgarden et al. 1988. Hughes 1990). Depending on whether the system is closed or open, reproductive phenology within the local population may or may not be coupled with the recruitment event. Algal reproductive prod- 
ucts (i.e. spores, gametes, or zygotes) usually have a short dispersal range (Hoffman 1987). This would suggest that the algal system is closed. However, Amsler \& Searles (1980) found spores of the green alga Enteromorphasp. $35 \mathrm{~km}$ away from the nearest known population. In contrast, Vadas \& Wright (1986) found no successful recruitment of the brown alga Ascophyllum nodosum (L.) Le Jolis over 20 yr, despite the presence of reproductive plants within the population during the same period.

There is a good indication that the Fucus population from False Creek is a closed system. The pattern of recruitment has been shown to follow the reproductive phenology (Ang 1991a). Within a closed system, population size can be regulated either through a densitydependent mortality of the recruits, or through a density-dependent regulation on the production of recruits, i.e. through reproduction.

Crowding appeared to have conveyed some advantages to the Fucus germlings at the early months of their development, as survivorship was better at high than at low densities (Fig. 2A). Schonbeck \& Norton (1978) observed that intertidal fucoids dried out more slowly at low tide and survived slightly better when in clumps than as individuals. Hruby \& Norton (1979) reported that the spores of various intertidal species survived better at high densities. Germlings of Fucus are tuft-like especially at high densities. Perhaps this offers the same advantage against desiccation and herbivory as was suggested for other tuft-forming algae. Hay (1981) showed that tuft-forming algae survived better in intertidal habitats because they suffered less physiological damage due to desiccation and lost relatively less biomass to herbivory than non-tuft-forming algae. In contrast, in a study to test the survival of the zygotes of Ascophyllum nodosum exposed to simulated intertidal water movement, Vadas et al. (1990) found zygotes survived better at medium and low densities than at high density, at different setting times (sensu Vadas et al. 1990: time allowed for the zygote to attach to the substratum). They suggested that this may be partly due to an enhanced bacterial growth that was associated with high zygote densities, especially at longer setting times. However, survivorship, as used in their context, is mainly an indication of the number of zygotes that was not dislodged from the pottery chips (settling plates) after being exposed to simulated water movement for 1 min, compared to those on the control chips that were placed in calm water. Their results do not indicate a density-dependent response over time and therefore cannot be compared with those in our study. Nevertheless, their results indicate that it was perhaps more difficult for the zygotes to attach more firmly to the substratum (settling plate) at high densities.
Fucus germlings seeded in spring or summer did not seem to have benetited from crowding. None of them survived through the summer months. Prolonged exposure to high temperature and desiccation during summer low tide appeared to be a strong density-independent factor that eliminated whatever advantage crowding may have on early germling survival.

The positive effect of density on mortality (Fig. 2B) for plants more than 2 mo old suggests that competition probably became more important once the plants had grown beyond the initial stage. A negative effect of density on mortality was not detected in plants from the density squares. Other density studies on algae likewise did not observe any negative effect (Black 1974, Schiel \& Choat 1980, Chapman \& Goudey 1983, Chapman 1984, Dean et al. 1989). These studies were mainly based on plants already quite large, i.e., beyond the germling stage. Presumably, if such a negative effect were to occur only during early development, it would have been missed in these studies. This is likely to be the case for the plants in the density squares. Fucus plants in the density squares showed a significant relationship between density and mortality only in the first few months. Similar observations have been made by Black (1974). He reported that a significant positive effect of density on mortality in Egregia laevigata (Setchell) was detected only in the first few months beyond which mortality became density-independent. The density of plants among density blocks became non-significantly different beyond September 1987 so any difference in mortality beyond this period would not have been due to density. Other than density, many other factors such as physiology and intrinsic growth rate could also affect the mortality rate of Fucus plants. This is reflected in the low variation accounted for by the regression line describing this relationship in both the density blocks and density squares.

In higher plants, mortality rate usually increases with increasing density (e.g. Harper 1977. Antonovics \& Levin 1980, Weiner \& Thomas 1986j. The effect of density is also often expressed in terms of plant yield or plant weight. Although we have evaluated the effect of density on Fucus in terms of Fucus plant length, there is a very highly significant relationship between plant length and plant dry weight (linear regression: log dry $w t=2.146 \log$ length $-2.359, \mathrm{r}^{2}=0.917, \mathrm{n}=2511$, $p<0.001$, unpubl. data; see also Ang 1992, Fig. 1). Hence, similar effect of density would have been detected if the size dimension used were plant weight rather than plant length. Watkinson (1985) noted that only about $20 \%$ of the variation in individual plant yield in higher plants can be accounted for by size and proximity of neighbouring plant(s). He further noted that the different measures used to estimate the level 
of crowding, like number of neighbours within a given area, assume that competition between plants is 2 -sided. In reality, competition is often asymmetrical and a plant that managed to become bigger earlier than the others tends to exert considerably more effect on smaller plants, and not vice versa, thus leading to dominance and the suppression of these smaller plants (Watkinson 1985, Schmitt et al. 1986, 1987).

It is not difficult to understand that a similar mechanism of dominance-suppression can be operating in algal populations resulting in size inequality within the populations and increased mortality of the smaller plants. Competition among individual algal plants is conceivably less complicated than in higher plants simply because of the absence of a belowground component. Although in some cases, holdfasts may compete for space with neighbouring plants. Dean et al. (1989) and Reed (1990) suggested that the effect of shading by an algal canopy was one of the key factors influencing growth and survival in subtidal algal populations of Macrocystis pyrifera (L.) C. Ag. and Pterygophora californica Ruprecht respectively, through dominance and suppression. Other research has been less supportive of this mechanism. Chapman (1984, 1986) did not find smaller plants of Laminaria longicruris Pyl. to suffer a significantly greater mortality than larger plants. Higher growth rate at higher density was also reported for Sargassum sinclairii Hook. et Harv. (Schiel \& Choat 1980, Schiel 1985) and Carpophyllum maschalocarpum (Turn.) Grev. (Schiel 1985). Shading is likely to be a key factor in intertidal algal competition as well, especially for relatively large algae like Fucus. Light may have been important for growth between fall and early winter of 1986 such that shading reduced the growth rates of more crowded plants in the density squares. This suppression was apparently released in mid winter, when presumably growth was more limited by other factors and plants at higher density were able to cope with them better than those at lower density. Over this same period, plants on the settling blocks were in a different stage of development. It is interesting to note that these germlings also responded positively to crowding, but with higher survivorship rather than with higher growth rate. Whether this response could be attributed directly to shading is, however, less clear. During summer low tide, canopy shading may play a different role for the understory individuals by providing protection from desiccation. As suggested in Ang (1991a), this mechanism could improve the chances of survival of Fucus germlings and make possible the existence of a 'germling bank'. On the other hand, prolonged exposure during summer low tide may exert a heavy toll on the larger plants (Ang 1991b).

The sizes of the plants in the high density blocks be- came significantly different at the very early stage of development, whereas the plants on mid and low density blocks became different in size at a much later time. While the initial advantage of crowding may be in increasing the chances of survival, competition or other regulating processes probably took place, and dominance-suppression was in effect earlier when the plants were more crowded.

The significant correlation among all 3 measures of size distribution, $g_{1}, C V$, and $G$, over time suggests that whether expressed in terms of the shape of size distribution or in terms of size inequality, frequency distribution of sizes among plants in the density blocks or the density squares varies in relatively the same way. In the absence of selective mortality, dominance-suppression should further exaggerate size inequality and lead to greater positive skewness, i.e. fewer large and more smaller individuals. Selective mortality of either the larger or smaller planis would tend to obscure this pattern. There appeared to be a general trend towards positive skewness in density blocks from winter to spring. This may be due to a greater mortality of the small plants over this period. However, the trend became less consistent in summer probably due to increased mortality of the larger plants (Ang 1991b). This seems to be the case for the density squares as well.

Turner \& Rabinowitz (1983) argued that size inequality in an even-aged population may simply be a result of inherent difference in the intrinsic growth rate among individuals. When the density blocks were initially set out in the field in November 1986, some germlings were already observed to be slightly bigger than the others. These could be the ones that eventually dominated the others. However, because the blocks were seeded over a period of at least a week during which different pulses of eggs would have settled, it is not certain whether these bigger germlings were bigger because they were discharged and settled earlier, hence had more time to grow, or that they grew faster than the others because of their inherent genetic make up. Both the quality of the germlings and timing of settlement are probably important in determining the size structure of the population, which may then be further modified through the process of dominance and suppression.

In both the density blocks and density squares, the populations started out with different densities but eventually converged to a similar final density. This final density may indicate the carrying capacity for a given surface area. Only a few large plants of about similar sizes survived until the end of the experiment.

Density studies on algal populations are usually evaluated at the population level rather than at the level of the individuals. Density is rarely expressed in terms of distance from the nearest neighbour (but see 
Reed 1990), but rather in terms of a mean value. This is largely because of the difficulty in experimentally manipulating the desired distance between plants. It is possible that plants in populations of a lower mean density may be experiencing as much interference from their neighbours as plants growing in higher mean densities, especially if the distribution of the plants is clustered. Individuals in the thinned density squares were more or less kept equidistant from their neighbours. They showed as much variation in size and chances of mortality as those in low and high density squares. Further studies emphasizing neighbourhood relationship are needed to clarify the effect of density at the individual level.

The plastic response of higher plants to density is usually a developmental phenomenon. Under crowded conditions, increased mortality results in thinning and reduction in mean size results in a constant final yield. A similar response has been documented in algae (e.g. Adams \& Austin 1979, Harger \& Neushul 1983, Neushul \& Harger 1985). A different but nonetheless interesting response has been shown in sea urchins where large urchins responded to overcrowding by becoming smaller (Levitan 1989). It is not known if a similar response is possible in algae. It may be that if an algal population becomes more crowded, it is the new recruits that would become suppressed in growth. Increased crowding did not seem to affect the bigger or already well-established individuals (pers. obs. on permanent quadrats). While individuals of Fucus from False Creek do not exhibit periodic die back, it would be interesting to examine how those other species with perennating holdfasts respond to crowding. Regeneration from a perennating holdfast may be more advantageous than from new recruits, as in Sargassum spp. (Ang 1985a, b) where new shoots started to develop well before the older erect parts died back or new plants had a chance to be recruited. Dominance by the regenerated plant is thus maintained.

Individuals on the density blocks formed an evenaged stand. Those on the density squares were more probably of mixed age. Although the results from the density blocks and density squares were generally similar, intercohort interactions may account for part of the variations observed in the density squares. However, details of these interactions, if any, were not detectable with our experimental designs. Intercohort interactions may effect a lower recruitment rate as reported in some subtidal algal populations (Dayton et al. 1984, Reed 1990).

Potential reproductive output of Fucus has been shown to be size-dependent (Ang 1991a). None of the plants in the density blocks or density squares were reproductive at the time when the density among blocks or squares became non-significantly different. Less than 10 of those that remained eventually became reproductive in the following year. The absence of significant size difference among plants from the density blocks during the later part of the experiment suggests that reproductive output is probably independent of the initial density. This conclusion can only be tentative because of the small sample size and is in contrast to the negative effect of density on reproduction observed in Pterygophora californica sporophytes (Reed 1990). Except for a recent study by Reed et al. (1991) which showed that female gametophytes of $P$. californica and Macrocystis pyrifera matured later at higher settlement density and never produced gametes at extremely high density of $\mathrm{ca} 3000 \mathrm{~mm}^{-2}$, it is not known if density would affect other aspects of algal reproduction like timing and mode (vegetative vs sexual) similar to that observed in some higher plants (Weiner 1988).

The effect of herbivores has not been evaluated in these experiments. The main grazers are littorines and amphipods. Brawley \& Adey (1981) found that micrograzers like amphipods significantly altered the algal community structure of a coral reef microcosm. Reed (1990), however, found that while the abundance of macrograzers such as sea urchins and sea hares may be correlated with Pterygophora density, the amount of plant tissue lost due to grazing and/or abrasion probably was not. Herbivory has been considered to be a key factor in structuring some intertidal and subtidal algal communities (see reviews by Lubchenco \& Gaines 1981, Hawkins \& Hartnoll 1983). Responses of herbivores to algal density and the direct or indirect effects of these responses on performance of the algae remain to be clarified.

Results from our study indicate that regulation of the Fucus population in False Creek is probably mediated through a density-dependent mortality of the recruits. This would probably be important only at the initial stages of plant development. However, given the large variation indicated in the data (i.e. low percentage of variation accounted for by most regression lines), these results should be taken in the light of Strong's (1986) argument that there is hardly a simple and explicit density relationship with demographic performances in any real population. Both physical and biological factors are likely to add to the variance of any density relationship and introduce vagueness into the relationship. Such density-vague relationships differ from density-dependent relationships in suggesting a strong stochastic element in population regulation. Further experimentation is necessary to explore the characteristics of this relationship.

Acknowledgements. This study was partially funded by Natural Science and Engineering Research Council of Canada grant no. 5-89872 to R. De W., and by a Sigma Xi 
grants-in-aid to P.O.A. Critical comments from P. G. Harrison, $T$ Norton, R. Turkington and the anonymous reviewers greatly improved the earler drafts of the manuscript. P.O.A held an University of British Columbia (UBC) graduate fellowship, an International Centre for Ocean Development fellowship, an Edith Asthon Memoral Scholarship (UBC), and a Kit Malkin Scholarship (UBC) during the duration of this study. The revision of the manuscript was undertaken during P.O.A tenure as a post-doctoral fellow at the Halifax Fisheries Research Laboratory, Fisheries and Oceans Canada.

\section{LITERATURE CITED}

Adams, R. W., Austin, A. (1979). Potential yields of Jridaea cordata (Florideophyceae) in natural and artificial populations in the northeast Pacific. Proc. Int. Seaweed Symp. 9: 499-507

Amsler, C. D., Searles, R. B. (1980). Vertical distribution of seaweed spores in a water column offshore of North Carolina. J. Phycol. 16: 617-619

Ang, P. O. (1985a). Studies on the recruitment of Sargassum spp. (Sargassaceae, Phaeophyta) in Balibago, Calatagan, Philippincs. J. exp. mar. Biol. Ecol. 91. 293-301

Ang, P. O. (1985b). Regeneration studies of Sargassum siliquosum J Ag. and S. paniculatum J. Ag. (Sargassaceae, Phaeophyta). Botanica mar. 28: 231-235

Ang, P. O. (1991a). Natural dynamics of a Fucus distichus (Phaeophyceae, Fucales) population: reproduction and recruitment. Mar. Ecol. Prog. Ser. 78: 71-85

Ang, P. O. (1991b). Age- and size-dependent growth and mortality in a population of Fucus distichus. Mar Ecol. Prog. Ser 78: 173-187

Ang, P. O. (1992). Cost of reproduction in Fucus distichus. Mar. Ecol. Prog. Ser. 89: 25-35

Antonovics, J., Levin, D. A. (1980). The ecological and genetic consequences of density dependent regulation in plants. Ann. Rev. Ecol. Syst. 11: 411-452

Bendel, R. B., Higgins, S. S., Teberg, J. E., Pyke, D. A. (1989). Comparison of skewness coefficient, coefficient of variation, and Gini coefficient as inequality measures within populations. Oecologia 78: $394-400$

Black, R. (1974). Some biological interactions affecting intertidal populations of the kelp Egregia laevigata. Mar Biol. 28: $189-198$

Brawley, S. H., Adey, W. H. (1981). The effect of micrograzers on algal community structure in a coral reef microcosm. Mar. Biol. 61: 167-177

Chapman, A. R. O. (1984). Reproduction, recruitment and mortality in two species of Laminaria in southeast Nova Scotia. J. exp. mar. Biol. Ecol. 78: 99-110

Chapman, A. R. O. (1986). Age versus stage: an analysis of age and size specific mortality and reproduction in a population of Laminaria longicruris. J exp. mar. Biol. Ecol. 97 : $113-122$

Chapman, A. R. O., Goudey, C. L. (1983). Demographic study of the macrothallus of Leathesia difformis (Phaeophyta) in Nova Scotia. Can. J. Bot. 61: 319-323

Dayton, P. K., Currie, V., Gerrodette, T., Keller, B. D., Rosenthal, R., Ven Tresca, D. (1984). Patch dynamics and stability of some California kelp communities. Ecol. Monogr. 54 : $253-289$

Dean, T. A., Thies, K. Lagos, S. L. (1989). Survival of juvenile giant kelp: the effects of demographic factors, competitors and grazers. Ecology 70: 483-495

Edmeades, G. O., Daynard, T B. (1979). The development of plant-to-plant variability in maize at different planting densities. Can. J. Plant Sci. 59: 561-576
Ford, F. D. (1975). Competition and stand structure in some even-aged plant monocultures. J. Ecol. 63: 31.1-333

Harger, B. W W., Neushul, M. (1983). Test-farming of the giant kelp, Macrocystis, as a marine blomass producer. J. World Maricult. Soc. 14: 392-403

Harper, J. L. (1977). Population biology of plants. Academic Press, New York

Hawkins, S. J., Hartnoll, R. G. (1983). Grazing on intertidal algae by marine invertebrates. Oceanogr. mar. Biol. A. Rev. 21: 195-282

Hay, M. E. (1981). The functional morphology of turf-forming seaweeds: persistence in stressful marine habitats. Ecology 62: 739-350

Hoffmann, A. J. (1987). The arrival of seaweed propagules at the shore: a review. Botanica mar. 30:151-165

Hruby. T., Norton, T A. (1979). Algal colonization on rocky shores in the Firth of Clyde. J. Ecol. 67: 65-77

Hughes, T P. (1990). Recruitment limitation, mortality, and population regulation in open systems: a case study. Ecology 71: 12-20

Kleinbaum, D. G., Kupper, L. L. (1978). Applied regression analysis and other multivariate methods. Duxbury Press, North Scituate, Mass.

Levitan, D. R. (1989). Density-dependent size regulation in Diadema antillarum: effects on fecundity and survivorship. Ecology 70: 1414-1424

Lubchenco, J., Gaines, S. D. (1981). A unified approach to marine plant-herbivore interactions. I. Populations and communities. Ann. Rev. Ecol. Syst. 12: 405-437

Neushul, M., Harger, B. W. W. (1985). Studies of biomass yield from a near-shore macroalgal test farm. J. Sol. Energy Sci. Eng. 1.07: 93-96

Reed, D. C. (1990). An experimental evaluation of density dependence in a subtidal algal population. Ecology 71 : 2286-2296

Reed, D. C., Neushul, M., Ebeling, A. W. (1991). Role of settlement density on gametophyte growth and reproduction in the kelps Pterygophora californica and Macrocystis pyrjfera (Phaeophyceae). J. Phycol. 27: 361-366

Roughgarden, J., Gaines, S., Possingham, H. (1988). Recruitment dynamics in complex life cycles. Science 241: $1460-1466$

Schiel, D. R. (1985). Growth, survival and reproduction of two species of marine algae at different densities in natural stands. J. Ecol. 73: 199-217

Schiel, D. R., Choat, J. H. (1980). Effects of density on mono specific stands of marine algae. Nature 285: 324-326

Schmitt, J., Eccleston, J., Ehrhardt, D. W. (1987). Dominance and suppression, size-dependent growth and self thinning in a natural Impatiens capensis population. J. Ecol. 75: $651-655$

Schmitt, J., Ehrhardt, D. W., Cheo, M. (1986). Light-dependent dominance and suppression in experimental radish populations. Ecology 67: 1502-1507

Schonbeck, M. Norton, T A. (1978). Factors controlling the upper limuts of fucoid algae on the shore. J. exp. mar. Biol. Ecol. 31: 303-313

Strong, D R. (1986). Density-vague population change. TREE 1: $39-42$

Turner, M. D., Rabinowitz, D. (1983). Factors affecting frequency distribution of plant mass: the absence of dominance and suppression in competing monocultures of Festuca paradoxa. Ecology 64: 469-475

Underwood, A. J. (1981). Techniques of analysis of variance in experimental marine biology and ecology. Oceanogr. mar. Biol. A. Rev. 19: 513-605 
Vadas, R. L., Wright, W. A. (1986). Recruitment, growth and management of Ascophyllum nodosum. Actas I[. Congr Algas mar chil. 2: 101-113

Vadas, R. L., Wright, W. A., Miller, S. L. (1990). Recrutment of Ascophyllum nodosum: wave action as a source of mortality. Mar. Ecol. Prog. Ser. 61. 263-272

Watkinson, A. R. (1985). Plant responses to crowding. In White, J. (ed.) Studies on plant demography: a festschrift for John L. Harper. Academic Press, London, p. 275-289

Weiner, J. (1988). The influence of competition on plant re-

This article was submitted to the editor production. In: Lovett Doust, J., Lovett Doust, L. (eds.) Plant reproductive ecology. Patterns and strategies Oxford Univ. Press, New York, p. 228-245

Weıner, J., Thomas, S. C. (1986). Size variability and competition in plant monocultures. Oikos 47: 211-222

Weiner, J., Solbrig, O. T (1.984). The meanıng and measurement of size hierarchies in plant populations. Oecologla 61: $334-336$

Wilkinson, L. (1988). SYSTAT: The system for statistics. SYSTAT, Inc., Evanston, Illinois

Manuscript first received: October 14, 1991

Revised version accepted: November 6, 1992 